\title{
Artificial Intelligence combined with Hybrid FEM-BE Techniques for Global Transformer Optimization
}

\author{
E. I. Amoiralis ${ }^{1}$, P. S. Georgilakis ${ }^{1}$, M. A. Tsili ${ }^{2}$, A. G. Kladas ${ }^{2}$ \\ ${ }^{1}$ Department of Production Engineering \& Management, Technical University of Crete \\ ${ }^{2}$ School of Electrical \& Computer Engineering, National Technical University of Athens, \\ kladasel@central.ntua.gr
}

\begin{abstract}
The aim of the transformer design optimization is to define in detail the dimensions of all the parts of the transformer, based on the given specification, using available materials economically in order to achieve lower cost, lower weight, reduced size and better operating performance. In this paper, a hybrid artificial intelligence - numerical technique is proposed for the selection of winding material in power transformers. The technique uses decision trees for attribute selection and neural networks for winding material classification, along with finite element - boundary element modeling of the transformer for the calculation of the performance characteristics of each considered design. The accuracy of the proposed method is $\mathbf{9 5 . 5 \%}$ (classification success rate for the winding material on an unknown test set), which makes it very efficient for industrial use.
\end{abstract}

\section{INTRODUCTION}

The variation in the cost of the materials used in the transformer manufacturing has direct impact in the design of the technical and economical optimum transformer. The material of the transformer windings can be copper (CU) or aluminum (AL). In order to check which material results to a more economical solution, there is a need to optimize twice the transformer (once with $\mathrm{CU}$ and once with AL windings) and afterwards to select the most economical design. The solution of winding selection problem can be implemented using Artificial Intelligence (AI).

\section{Proposed Methodology}

In this paper, decision tree (DT) is proposed for attribute selection and artificial neural networks (ANN) for winding material classification. The method is composed of the following steps:

1. Selection of candidate attributes, i.e. parameters affecting the selection of transformer winding material;

2. Creation of the learning and test sets;

3. DT training;

4. Attribute selection based on DT;

5. ANN training using the attributes selected by the DT;

6. Incorporation of the ANN model in the transformer optimization process as an efficient tool for winding material selection.

For the creation of the learning and test sets, 6 power ratings $(250,400,630,800,1000$ and $1600 \mathrm{kVA})$ and, 9 categories of losses are taken into account (according to CENELEC harmonization document 428.1 S1, 1992). Seven different unit costs (in $€ / \mathrm{kg}$ ) are considered for the $\mathrm{CU}$ and the $\mathrm{AL}$ winding. Based on the above, 69.7=378 transformer design optimizations with $\mathrm{CU}$ winding (CU designs) and 378 transformer design optimizations with $\mathrm{AL}$ winding (AL designs) are realized. For each design, either the CU design or the AL design is the final optimum design (with the least cost). In total, $6 \cdot 9 \cdot 7^{2}=2646$ final optimum designs are collected and stored into databases. The performance and parameters of each considered design (short-circuit impedance, no load loss etc.) are calculated with the use of a particular hybrid finite element - boundary element model, [1]. This model is particularly suitable for use with optimization algorithms, as it reduces the total time needed for the magnetic field calculation during each iteration and provides high accuracy, which is crucial during the design stage. The databases are composed of sets of final optimum designs (FOD) and each FOD is composed of a collection of input/output pairs. The input pairs or attributes are the 13 parameters shown in Table I. The output pairs comprise the type of winding (CU or AL) that corresponds to each FOD. The learning set is composed of 1350 sets of FODs and the test set has 1296 sets of FODs.

TABLE I

CANDIDATE ATTRIBUTES

\begin{tabular}{llll}
\hline Symbol & Attribute Name & Symbol & Attribute Name \\
\hline $\mathrm{I}_{1}$ & CU unit cost $(€ / \mathrm{kg})$ & $\mathrm{I}_{7}$ & Guaranteed FE losses $(\mathrm{W})$ \\
$\mathrm{I}_{2}$ & AL unit cost $(€ / \mathrm{kg})$ & $\mathrm{I}_{8}$ & Guar. winding losses $(\mathrm{W})$ \\
$\mathrm{I}_{3}$ & $\mathrm{I}_{1} / \mathrm{I}_{2}$ & $\mathrm{I}_{9}$ & $\mathrm{I}_{7} / \mathrm{I}_{8}$ \\
$\mathrm{I}_{4}$ & $\mathrm{FE}$ unit cost $(€ / \mathrm{kg})$ & $\mathrm{I}_{10}$ & Rated power $(\mathrm{kVA})$ \\
$\mathrm{I}_{5}$ & $\mathrm{I}_{4} / \mathrm{I}_{1}$ & $\mathrm{I}_{11}$ & Guar. short-circuit voltage (\%) \\
$\mathrm{I}_{6}$ & $\mathrm{I}_{4} / \mathrm{I}_{2}$ & $\mathrm{I}_{12}$ & $\mathrm{I}_{7} / \mathrm{I}_{10}$ \\
& & $\mathrm{I}_{13}$ & $\mathrm{I}_{8} / \mathrm{I}_{10}$ \\
\hline
\end{tabular}

III. RESULTS AND DISCUSSION

The trained DT has classification success rate $94.06 \%$ and $96.37 \%$, on the learning set and test set, respectively. In the various correlation nodes of the DT, the following 6 attributes are appearing: $\mathrm{I}_{3}, \mathrm{I}_{5}, \mathrm{I}_{7}, \mathrm{I}_{8}, \mathrm{I}_{9}$, and $\mathrm{I}_{13}$. In this way, the DT has automatically selected only 6 attributes among the 13 candidate ones. The selected ANN architecture is the threelayer feed-forward system with back-propagation. The number of input neurons is 6 , corresponding to the 6 attributes automatically selected by the DT. The output layer comprises a single neuron, corresponding to the optimum winding material. It was found that for 8 hidden neurons, the best classification results are obtained, namely $97.77 \%$ for the learning set and $95.52 \%$ for the test set.

The ANN model for winding selection has been incorporated in the transformer design optimization. This development divides by two the effort of the designer to optimize the transformer.

\section{REFERENCE}

[1] M. A. Tsili, A. G. Kladas, P. S. Georgilakis, A. T. Souflaris, D. G. Paparigas, "Geometry Optimization of Magnetic Shunts in Power Transformers Based on a Particular Hybrid Finite Element - Boundary Element Model and Sensitivity Analysis," IEEE Trans.on Magn., Vol. 41, No 5, pp. 1776-9, May 2005. 